\title{
MARXISMO, EXISTENCIALISMO Y DERECHO
}

Pocas han sido todavía las tentativas de aplicar los esquemas de las actuales corrientes filosóficas a la elucidación de los grandes problemas del Derecho; especialmente, al más importante de todos: al problema de la justicia o, expresado en términos contemporáneos, a la búsqueda de criterios axiológicos que permitan una evaluación del Derecho positivo. Por regla general, los filósofos han evitado incursionar en un campo que consideraban secundario; a su vez, los juristas han manifestado una cierta desconfianza por todo tipo de investigación que, aún cuando les entreabriera enormes posibilidades al estudio de lo propiamente jurídico, les obligaba a navegar por aguas desconocidas y que carecen de la cómoda seguridad de tierra firme del Derecho positivo. Esto ha originado con bastante frecuencia un retraso de la Filosofia del Derecho respecto de la Filosofía General. Los jusfilósofos, cuando no se han mantenido dentro de los límites de un estrecho positivismo, han preferido apoyar sus posiciones sobre el Derecho en filosofías de relativa antigüedad cuya amplia vulgarización les permitiera adoptarlas como puntos de partida casi axiomáticos, ahorrándoles la discusión de sus premisas mismas. En gran parte de los casos, el resultado ha sido un jusnaturalismo contemplado a través del cristal de los sistemas creados durante los siglos XVII y XVIII; cuando el jusfilósofo ha alcanzado la crítica kantiana, surgen toda una gama de formalismos. $Y$ en los últimos años observamos la aparición de los sociologismos, aun cuando éstos no hayan tenido todavía una repercusión efectiva sobre la doctrina y sobre los ordenamientos jurídicos, salvo en los países anglosajones.

Nicos Ar. Poulantzas, filósofo y jurista, ha tenido el mérito de intentar nuevos caminos para el Derecho (1).

1 POULANTZAS, Nicos Ar.- Nature des Choses et Droit. Essai sur la dialectique du fait et de la valeur. Bibliothèque de Philosophie du Droit sous la direction de Ch. Eisenman, H. Batiffol et M. Villey. Vol. V. Librairie Générale de Droit et de Jurisprudence. Paris, 1965, 346 pgs.)
Griego de nacimiento, hizo sus estudios de abogado en su país de origen. Posteriormente, viajó a Alemania, donde estudió en las universidades de Heildeberg y de Munich, efectuando lecturas "inmensas" (según expresión de M. Villey) de filosofía alemana. Pasó a París, donde tomó contacto con J.P. Sartre, quien lo invitó a formar parte del equipo de redacción de "Les Temps Modernes", revista en la que ha publicado diversos trabajos. En 1965 sustentó con gran éxito ante la Facultad de Derecho de la Universidad de París una tesis para optar el grado de Doctor, que constituye el libro que comentamos en esta reseña. Actualmente es profesor en dicha facultad y además desempeña el cargo de investigador en Filosofía del Derecho del Centro Nacional de la Investigación Científica de Francia (C. N. R. S.). Asumiendo una posición marxista, ha pretendido conciliar esta filosofía con el existencialismo dentro de las pautas trazadas por J.P. Sartre en la "Crítica de la Razón Dialéctica" $y$, desde esta perspectiva, examinar el Derecho. El intento es doblemente interesante. De un lado, conocemos la importancia que asigna el existencialismo a la persona, al hombre, y a la preocupacićn eminentemente social del marxismo: merece atención cualquier ensayo de conciliación entre ambos. De otro lado, es también sabida la desconfianza que tanto el existencialismo como el marxismo profesan por el Derecho, sea como mundo del "SE", de la despersonalización, sea como instrumento de explotación de la clase dominante. En cambio, Poulantzas nos ofrece una Filosofia del Derecho precisamente existencial-marxista.

Todo lo dicho, agregado al hecho de que no existe aún traducción al castellano, nos llevan a realizar una exposición algo pormenorizada de las tesis del autor.

Para seguir más fácilmente el desarrollo del pensamiento de N. Poulantzas, es conveniente ante todo delinear el problema tratado. Esto resulta particularmente recomendable si se tiene en cuenta que el temperamento 
mediterráneo del autor, unido a su formación germánica, ha resistido tenazmente la influencia del cartesianismo expositivo francés; lo que hace indispensable conservar siempre presente el objetivo propuesto a fin de no perder a través de la obra el hilo que conduce el razonamiento.

Es así como el autor inicia el trabajo manifestando que el tema que se propone discutir es el de las relaciones entre el hecho y el valor, el ser y el debe ser. Ya la determinación del problema en estos términos nos lleva a comprender que Poulantzas se inserta dentro de la perspectiva filosófica contemporánea que adopta a Kant como punto de partida en tanto que fue este filósofo quien estableció la distinción entre hecho y valor. La superación del abismo creado entre el ser y el valor, nos dice Poulantzas, no puede consistir de Kant en adelante en negar la distinción sino, por el contrario, debe apoyarse en ella para lograr una unidad compleja de estos elementos.

Luego de plantearnos la razón de la distinción en la "inversión copernicana", en virtud de la cual el mundo exterior al sujeto se estructura a partir de éste, quien se erige así en el centro de la visión idealista del mundo, Poulantzas critica el formalismo al que conduce la concepción kantiana. Aclara que Kant en su Filosofía del Derecho no propone un positivismo jurídico - como ha sucedido con algunos neokantianos - que habria suprimido la distinción entre hecho y valor: en esa hipótesis, la ley positiva considerada como un hecho no tendria otro fundamento que una ley positiva-hecho superior. En cambio, para Kant la ley positiva-hecho no es una norma válida (éticamente) sino en la medida que encarna la racionalidad y la universalidad. Sin embargo, cae en el formalismo porque es tal la distancia entre hecho y valor que, habiendo despojado al hecho de toda significación, el valor no puede estar fundado en lo real concreto $y$ se reduce a una mera forma.

Ahora bien, Kant no fue fiel a sus planteamientos pues, tangencialmente, a través de su principio de no contradicción, transpone las convicciones de su tiempo y de la sociedad concreta en la que vive. Ese principio no es aplicado al imperativo categórico propiamente sino al campo de los hechos. Asi: el depósito debe ser restituido, porque la no restitución sería contradictoria con su naturaleza; pero ello implica la existencia de la propiedad privada que fundamente la existencia de esta institución. En el plano del imperativo categórico, dice Poulantzas, cada hombre habria estado en aptitud de levantar la contradicción no devolviendo el depósito y deseando que todos los hombres actúen de la misma manera, es decir, deseando que esta conducta sea erigida en ley universal. También a través de su noción de persona humana, Kant desliza contenidos empíricos. Nos dice que la persona debe ser considerada siempre como fin y nunca como medio. Pero la persona que merece esta digindad es el ser noumenal, el Otro en tanto que centro a su vez del imperativo categórico. Sin embargo, es imposible entrar en contacto con este hombre noumenal, ya que cada uno de nosotros sólo puede relacionarse con el hombre-fenómeno, con el ser empirico de los hombres. Es así como aplicando esta máxima y teniendo en cuenta en realidad al hombre empírico, Kant dedujo una profusión de reglas pretendidamente universales. $Y$ es que la antinomia irreductible entre hecho y valor, contenido y forma, hombre empírico y hombre noumenal, constituye necesariamente un callejón sin salida para los efectos de encontrar los fundamentos axiológicos del Derecho. Por eso Poulantzas concluirá su trabajo afirmando la existencia no ya de un dualismo radical, sino de una relación dialéctica del hecho y el valor en el seno de una totalidad estructural.

\section{I}

Planteado el problema en estos términos, sigamos a Poulantzas en el análisis que efectúa del mismo, primero a nivel ontológico: intentará ante todo descubrir las relaciones entre el hecho y el valor desde la perspectiva de una ontología del hombre.

Dentro de este orden de ideas, el autor estudia el tema desde un enfoque fenomenológico. Así, considera que la fenomenología contribuye a reconocer la especificidad científica del Derecho al otorgar realidad a todo correlato de la intencionalidad del sujeto: los valores son admitidos en cuanto tales y el estudio del Derecho adquiere dignidad de ciencia. Sin embargo, a mérito de la reducción o puesta entre paréntesis de la realidad (epojé) que preconiza, atribuye un carácter absoluto a las esencias eidéticas entre paréntesis cuyo sentido no se encontrará más en la relación originaria de sujeto-objeto. Es así como Reinach afirma que los conceptos jurídicos presentan ciertas estructuras ontológicas a priori en tanto que constituyen el presupuesto necesario de cualquier desarrollo de este concepto en un orden jurídico dado; este es el punto de partida de agudos análisis de la teoría fenomenológica sobre la propiedad, la promesa, la cesión de créditos, etc.

Ahora bien, es sabido - y Reinach lo acepta - que las reglas del Derecho positivo son siempre conformes 
con su esencia a priori. Esto nos plantea dos problemas graves: (a) ¿cómo pueden simplemente existir seres de Derecho positivo no conformes con su esencia? y (b) ¿cuál es la relación entre estas esencias eidéticas, entendidas como hechos, con los valores juridicos, con el fundamento axiológico del Derecho?

El primer problema no tiene solución, según Poulantzas. Admitiendo que estas esencias no son el resultado de una generalización empírica ni de una deducción a partir de una definición arbitraria, no es posible comprender cómo, si el "eidos" del crédito no permite sucesión según pretende Reinach, todas las legislaciones positivas establecen la cesión de créditos; salvo que consideremos las esencias desde un punto de vista platónico como trascendentes, lo que los fenomenólogos no aceptan. La raíz del problema estriba en que la reducción fenomenológica nos ha dejado entre manos un mundo fantasmagórico, puramente conceptual; pero el Derecho positivo no puede desviarse ni contradecir estos conceptos puros porque ambos tienen el mismo grado de realidad: desde el punto de vista fenomenológico, la regla concreta tiene la misma realidad que el "eidos" de la institución $y$ en ningún caso puede considerarse como un "menos-ser" con relación a éste. Por eso, nos dice Poulantzas, la fenomenología ha tomado una orientación platónica; pero lo que era posible para el platonismo no lo es para la teoría fenomenológica sin quebrar la unidad de ésta. En la práctica, esto lleva a la fenomenología a plegar los objetos para hacerlos entrar necesariamente en una esencia. Por tal motivo, el jurista fenomenólogo se ve arrastrado hacia conclusiones peligrosas: si afirma la existencia de un "eidos" de la propiedad individual, todas las restricciones sociales serán consideradas no como una característica esencial de la propiedad sino como variantes excepcionales; pero en esta forma encontramos en los conceptos lo que hemos puesto en ellos previamente, pues estamos definiendo el "eidos" de la propiedad a partir de ciertos elementos concretos de la propiedad individual.

El segundo problema - la relación entre las esencias eidéticas (el hecho) y el valor - nos ofrece también serias dificultades. Husserl considera que los valores también "son", tienen una esencia; pero el problema reside en saber en qué consiste el "ser" del valor. $Y$, aun cuando Husserl no insistió sobre este punto, parece admitir que el ser del valor es su "deber ser", es su normatividad misma. En este nuevo planteamiento de la separación abisal entre el ser-hecho (Sein) y el ser-valor (Sollen), encontramos el punto de partida de numerosas teorias contemporáneas del Derecho que sostienen que las ciencias jurídicas no deben ocuparse del contenido o del valor intrínseco de la norma, del fundamento axiológico del Derecho positivo, sino que debe colocarse a éste entre paréntesis a fin de considerar únicamente las relaciones lógicas de las normas en tanto que "seres normativos" (Normlogik). La norma no "es" sino que vale, dice Kelsen; el modo de ser del Derecho positivo es su validez, afirma más precisamente Gerhard Husserl. Aun cuando Kelsen no es propiamente un fenomenólogo (2), retiene sin embargo esta separacićn radical derivada de la epojé entre el ser de las normas y su contenido. Así cada norma no encuentra su fundamento sino en otra norma superior hasta alcanzar la grundnorm que "está ahi", evidenciada por su efectividad; pero esta efectividad no constituye su fundamento axiológico, según Kelsen, sino una mera comprobación de su existencia. Ahora bien, si hemos afirmado que toda norma válida constituye un valor en tanto que ser normativo y supone a su vez un valor previo que la funda y si mediante la epojé hemos reducido el valor a la normatividad pura sin referencia al contenido, no existe razón para detener en un determinado momento la cadena de normas ante una - la grundnorm - que ordena pero que no es ordenada, una cuya normatividad no nace de otro ser normativo anterior. En realidad, no queda sino aceptar - contra la opinión de Kelsen - que la grundnorm está axiológicamente fundada en su simple efectividad, que ésta constituye no la conditio per quam como pretende Kelsen sino la conditio sine qua non. Pero en este caso, el carácter antinómico del pensamiento kelseniano queda de relieve: ¿cómo fundar la norma, el valor, sobre un hecho si se ha adoptado como punto de partida la distinción radical entre hecho y valor?

Tratando de evitar estos escollos, Reinach y G. Husserl intentaron otros caminos: así el primero otorgó un carácter axiológico a las esencias aprióricas de las instituciones jurídicas; el segundo apoya los valores en su efectividad social. Pero en ambos casos topamos con el problema de fundar el valor en el hecho, habiendo aceptado como premisa su distinción. Por ese motivo, la teoria fenomenológica comprendió que sólo podía salvar distinción entre hecho y valor planteando la existencia de un mundo de valores, diferente del mundo de los hechos, en el cual los valores tuvieran su fundamento: se llevó

2 Luis Felipe Guerra en una reciente tesis sustentada en la Facultad sobre El Derecho Natural en el Pensamiento de Hans Kelsen (Lima, 1966) ha hecho notar las resonancias del método fenomenológico en la obra de este jurista. 
así la distinción hasta sus últimas consecuencias. Esta fue la posición de Scheler, quien afirmó la existencia de valores trascendentes, absolutos pero de contenido concreto, que eran susceptibles de ser aprehendidos por una intuición particular e inmediata. En esta forma quedaba resuelto tanto el problema ontológico como el axiológico. La influencia de Scheler sobre los filósofos contemporáneos ha sido notable. Sin embargo, Poulantzas considera que presenta los puntos vulnerables de toda filosofía de ińluencia platónica y, en todo caso, no puede fundar una noción de "naturaleza de las cosas", de sentido inmanente de lo real.

Poulantzas encontrará en el existencialismo los elementos necesarios para superar los problemas planteados por la fenomenología y reconciliar el hecho y el valor. Aceptando como estructuración primaria la relación sujeto-objeto que está en la base de la noción fenomenológica de intencionalidad, el existencialismo va a entenderla como la actividad práctica del hombre en el mundo. No debe colocarse al mundo entre paréntesis porque lo que interesa no es el conjunto inmutable de propiedades eidéticas de los "objetos" sino los objetos mismos a través de la experiencia intencional del sujeto. Es así como la noción de intencionalidad resulta sobrepasada por la de "ser-en-el-mundo" y los paréntesis caen. El existencialismo es, en primer lugar, una ontología del hombre. Este es libertad debido a su relación con el mundo, a su alejamiento permanente de sí mismo hacia el mundo exterior, debido a que, a diferencia de las cosas, no está fijado, determinado, cerrado sobre sí mismo; el hombre no está hecho, sino que se hace a través de sus operaciones existenciales: su existencia precede a su esencia. Es asi como su existencia se encuentra abierta al futuro que se presenta frente a él como tarea por realizar. $Y$ su realización consiste, como hemos dicho, en su acción sobre el mundo, en su trato con las cosas: el hombre es ante todo "ser-en-el-mundo". Ahora bien, todo acto en tanto que operación intencional supone un fin. Pero como este fin no puede encontrarse en una esencia humana en base a lo dicho, sólo puede tratarse de una proyección, una situación que el hombre se propone a sí mismo - que puede concebir, por tanto, como todavía no realizada - y que le permite evaluar la situación presente, le permite discernir entre sus actos en función de una mayor o menor adecuación al "proyecto". Ya aquí Poulantzas hace notar la proximidad respecto de este punto entre el existencialismo y el marxismo. Para este último, el hombre también es concebido en su relación con el mundo, en su inserción dentro de un universo de hombres y cosas. Para el marxismo, el hombre es carencia, es privación, es necesidad, en tanto que ser natural; pero el hombre, además de ser natural, es ser humano: lucha por la conquista de la naturaleza, humanizándola con su acción y adquiriendo en esta lucha su propia existencia y libertad. $Y$ aún cuando el marxismo parte más bien de una relación entre el contorno natural y material del hombre y su actividad, el existencialismo no puede prescindir de este aspecto material al considerar al hombre "en situación", al hombre como "ser-concreto-en-el-mundo-concreto".

Dentro de este orden de ideas, ¿cómo podemos entender la relación entre hecho y valor? Si nuestro "proyecto" plantea una situación como deseable es porque se ha producido una ruptura con "lo dado", es que se ha estimado la situación presente como no deseable y que, en consecuencia, "debe ser" cambiada. Este proceso lo señala Poulantzas como génesis de valor. Así, el valor es el resultado siempre de la experiencia intencional del hombre a través del acto y del proyecto. No significa esto que se excluya la posibilidad de ciertos valores colectivos que existen "ya ahi", que estén en frente de nosotros como "objetos". Sin embargo, también en esta hipótesis el valor es siempre un proyecto, una significación humana: esos valores colectivos han sido constituidos por proyectos humanos y son simplemente una "acumulación de sentido"; además, suponen inevitablemente un acto de adhesión personal, suponen que sean asumidos como proyectos propios. También aquí Poulantzas relaciona al existencialismo con la teoría marxista del trabajo que, según el autor, no puede ser concebida únicamente como trabajo "económico" sino como trabajo "humano", y como conquista por el hombre de su humanidad a través de sus actos.

Planteado el valor como opción existencial, las nociones de hecho y valor no aparecen ya como radicalmente separadas sino, por el contrario, como dos momentos del acto humano. Aún siendo totalmente diferentes, el hecho $y$ el valor se encuentran ligados en el interior de la existencia humana. El hecho es negado por el valor y la negación a su vez de este último como categoria independiente del hecho crea la dinámica de valorización del mundo, que se manifiesta en la acción del hombre. En esta forma, Poulantzas sostiene que hecho y valor constituyen una totalidad estructural en el interior de la cual estos elementos mantienen una relación dialéctica. Advirtamos que este planteamiento tiene la virtualidad de que, sin abandonar la distinción entre hecho y valor como sucedería si sometemos el hecho al valor o el valor al hecho, hace posible superar el abismo creado por 
Kant entre ambas nociones y resolver las contradicciones lógicas a que esta separación nos conducía.

Sin embargo, queda aún una dificultad importante por resolver. Si denominamos valores a los fines humanos - para Sartre, fin es el móvil erigido en valor - ino nos lleva esto a afirmar la existencia humana como un puro surgimiento? ¿No estamos instaurando un primado de la mera intensidad? En base a lo expuesto los actos criminales constituirian también valores; el Mal sería tan valor como el Bien. Poulantzas ha visto la objeción y para sortearla distingue los valores "válidos" de los valores "no-válidos" utilizando para ello la noción existencialista de la autenticidad. El hombre puede ocultarse a sí mismo la verdad de su existencia, huir del riesgo permanente del acto libre y buscar refugio en la "cosificación" rehusando elegir: ésta sería la existencia inauténtica que nos sumerge en el mundo impersonal del "SE" denunciado por Heidegger ("se" dice, "se" hace, "se" piensa, etc.). En cambio, la existencia auténtica será la que asuma plenamente su condición de hombre, la que se esfuerce en personalizar el mundo afirmándose en la relación con las cosas, la que se oriente a obtener grados cada vez mayores de libertad, de responsabilidad, de participación, de "compromiso". Es así como podemos no solamente evaluar el mundo mediante los valores, sino incluso evaluar el contenido de estos valores prácticos, de estos proyectos humanos: el hombre es libre y por consiguiente, debe escoger su libertad.

Poulantzas ha llegado asi a fundar una ética sobre la "naturaleza de las cosas", entendiendo por este término no ya una esencia predeterminada sino la totalidad de hecho y valor en el seno de la exisiencia humana. Pero esto no basta para valorizar el Derecho: éste es un mecanismo de regulación social $y$, por consiguiente, supone la existencia de una relación ontológica primaria entre "yo" y los "otros". La naturaleza de esta relación influirá notablemente sobre el concepto de Derecho según se coloque el énfasis en lo individual o en lo social. Por esta razón, después de haber estudiado el problema del valor a nivel de una existencia, es preciso repensarlo desde una perspectiva social: se trata esta vez de encontrar un sentido a la relación de "yo" con los "otros" que nos permita completar nuestra concepción del valor.

La posición filosófica que asumió Kant no le permitía fundar una relación ontológica entre sujetos, por cuanto que para este filósofo la verdadera esencia humana es noumenal y, en cambio, la alteridad sólo surge en el plano empírico: son los hombres-fenómeno que se pre- sentan ante el hombre noumenal. Husserl plantea la existencia de una socialidad originaria que encuentre a través del problema de la objetividad y de una experiencia inmediata del otro; pero las dificultades del kantismo se hacen aquí también presentes por cuanto que, habiendo privilegiado al sujeto trascendental por la puesta del mundo entre paréntesis, resulta difícil comprender cómo es posible entrar en contacto con el Otro en la constitución misma de sus significaciones. Scheler sostiene que solamente podemos atribuir como de otro las experiencias que empíricamente comprobamos como experiencias de otro, en la medida que concebimos al otro como sujeto de experiencias y a nosotros mismos como sujetos para otro; se entreteje asi una socialidad basada en que no es posible comprender incluso nuestras experiencias como propias sino únicamente cuando nos distanciamos de ellas para concebirlas como experiencias posibles también de otro sujeto: desde dentro, sólo podemos "vivir" nuestras experiencias. Es así como la experiencia del "yo" y del "otro" queda envuelta por la experiencia del "nosotros".

Poulantzas se ubicará también en este caso dentro del pensamiento existencial-marxista. Heidegger señala la reciprocidad ontológica de los seres humanos al encontrar que el mundo que nos rodea y nuestro propio ser está cargado de significaciones que "otros" sujetos han creado. Entonces, si los otros tienen tal importancia en la constitución de mi ser y de mi mundo es que soy yo mismo un ser-en-común, un ser-con (Mitsein). El "otro" no es un objeto cuya significación está enteramente determinada por mí sino es otro sujeto en cuya compañía puede conquistar el mundo. Lamentablemente, otros aspectos de la filosofía de Heidegger lo alejan de una autenticidad de la existencia social que queda como una simple trampa que conduce a la alienación. Sartre comprende la autenticidad de lo social pero la convierte en conflicto: el otro nos petrifica y nos roba nuestro mundo al asignarle sus propias significaciones; por eso, cada uno busca "cosificar" al otro para evitar ser "cosificado" por el otro. Según Poulantzas, es posible aceptar las precisiones de Sartre, que lo acercan a Hegel, sin tener que renunciar al mitsein de Heidegger: "yo y el otro nos erigimos en presencia recíproca por una génesis mutua del uno por el otro no exenta de contradicciones pero que nos une en nuestra conquista común del mundo"; pero esta relación no adquiere su verdadero sentido sino dentro de las perspectivas históricas y sociales cuya base constituye. Estos planteamientos concuerdan con la tesis de Marx en tanto que para éste el trabajo (que Poulantzas entiende en su sentido más 
general y no solamente económico) es la mediación "práctica" y existencial entre el hombre y el mundo $y$, desde ese ángulo, es el punto de encuentro con los demás hombres.

Hemos establecido de esta manera dos índices o criterios axiológicos que nos permitirán descubrir cuáles son los "valores válidos": de un lado, el hombre "debe" escoger su libertad; de otro lado, el hombre "debe" escoger la libertad de los demás. Ahora bien, el Derecho representa una importante tentativa de concretar estas actitudes ontológicas fundamentales del "ser-en-el-mundo" y del "ser-con-otros". A través de las relaciones jurídicas, los hombres se vinculan con el mundo y entre si en tanto que "sujetos", aceptando la libertad de los otros y realizando su propia libertad. Cabe notar que reconocer al otro como sujeto es considerarlo como creador de valores en el interior de una sociedad concreta. Por consiguiente, los valores establecidos que el hombre encuentra "ahi" - los ordenamientos jurídicos, entre ellos - son cristalizaciones de este actuar de los hombres, que cada hombre debe asumir descubriendo en ellos "el contenido particular que la libertad humana reviste en un cierto momento de la historia de la humanidad".

\section{II}

Los planteamiento que nos han permitido encontrar a nivel ontológico esta totalidad estructural del hecho y el valor, nos llevan necesariamente a transponer el problema en términos sociológicos. En efecto, si hemos caracterizado al hombre como "ser en situación", como seren-el-mundo haciéndose a sí mismo en su trato con las cosas, compartiendo su existencia con otros sujetos, la libertad sólo puede entenderse como libertad concreta, la totalidad del hecho y el valor se expresa en una situación histórica y social determinada, en una palabra, en un contexto sociológico: la existencia del hombre se desarrolla como "praxis" social, según el término creado por Marx, es decir, como actividad colectiva, social e histórica de los hombres; o mejor, la "praxis" es el modo de ser de los hombres conquistando en común el mundo en que viven. Esto significa que una Filosofía del Derecho, como la que hemos expuesto, desemboca necesariamente en una Sociologia del Derecho.

Sin embargo, antes de seguir adelante es preciso hacer una advertencia. Después de haber aceptado que el orden jurídico se fundamenta axiológicamente en esta totalidad dialéctica, no nos está permitido, al pasar al plano sociológico, al plano de la actividad humana que materializa y concreta esta actitud del hombre-en-el-mundo, no nos está permitido recaer en un simple amor fati, como les ha sucedido a algunos sociólogos. Indudablemente, los valores pueden constituir "hechos" observables, que encontramos "ya ahi", sea como un sistema de normas o conductas jurídicas, sea como aspiraciones sociales objeto de una investigación sociológica, etc. Pero en todos estos casos se trata de una visión "externa" del valor, de un estudio "desde fuera" en tanto que hecho, en tanto que objeto que se presenta a un sujeto "sociólogo"; se deja así de lado la dimensión "interna" del valor como acto del sujeto, como creación de sentido. Desde ese punto de vista no es posible fundar ningún juicio de valor; no hay paso del indicativo al imperativo, del sein al sollen, sino relación dialéctica en el interior de la existencia humana. Por eso, el planteamiento sociologista no funda en realidad el valor sobre el "hecho" social sino sobre una evaluación no reconocida de ese hecho.

Por consiguiente, la sociología que nos ayudará a materializar la libertad no será esa sociología puramente "objetivista" que, a través de una observación exterior de los valores jurídicos considerados como "hechos" sociológicos, pretende explicarlos o describirlos. Dentro del orden de ideas expuesto, hace falta concebir la sociología como una disciplina "comprensiva" que estudie el valor como "libertad en situación" y lo "comprenda" evaluándolo con los valores personales del observador o sociólogo: se exige así una sociologia normativa en la que se produce una identidad parcial entre sujeto y objeto de la ciencia, pues el sociólogo es autor y espectador, constituye parte integrante del todo social que estudia y su propia labor es parte de la "praxis" social. Por eso, afirma Poulantzas, en el terreno sociológico no puede entenderse la objetividad científica como distanciamiento o exteriorización sino como descubrimiento de una universalidad de sentido. Todo lo cual implica la búsqueda de nuevos esquemas metodológicos operativos que superen la mera explicación causal o la simple descripción de los valores jurídicos.

Un primer paso en este sentido fue la formulación por Max Weber de su teoria del "tipo ideal" que, aun cuando no tiene por objeto constituir una sociología normativa, recurre a la "comprensión", es decir, a la integración de los valores del observador en el objeto observado. Weber proponía que el observador o sociólogo elabore una imagen mental del fenómeno social a estudiarse, mediante una "racionalización utópica". Esta imagen servirá de modelo o marco teórico para el estudio 
sociológico; pero a su vez este modelo es una estructuración del objeto de la investigación realizada en base a los valores propios del investigador. Así cuando Weber estudia la influencia de la ética protestante en el nacimiento del capitalismo, estructura un "capitalismoobjeto de investigación sociohistórica" en función de aquellas notas del capitalismo que para él revisten un carácter significativo: la racionalización del trabajo, el uso de la técnica, etc., y son éstos, rasgos que busca en la ética protestante. Pero, desde otra perspectiva de significaciones, posiblemente el "tipo ideal" del capitalismo habría sido distinto. Poulantzas hace notar que este esquema no es utilizable para el fin antes señalado, debido a que no rinde cuenta de la totalidad social sino que, por el contrario, disgrega la realidad social en un gran número de hipótesis explicativas sin ninguna estructuración entre sí. Por eso propone como esquema la noción de estructura, cuyo rasgo fundamental reside en su carácter de totalidad: Io social constituye un todo, y así cada elemento no adquiere sentido sino considerado dentro del todo y a su vez este todo exige ser considerado en relación con cada una de sus partes o elementos; además, cualquier modificación de uno de los elementos conlleva una modificación de todos los otros, dado que la significación de cada elemento depende en cierta forma de la totalidad. Ahora bien, dado que esta estructura tiene por fuente la actividad práctica de los hombres que es ontológicamente temporal, las estructuras sociales y juridicas tienen también necesariamente una dimensión diacrónica. Por tanto, la idea de totalidad debe pensarse más bien como totalización, es decir, "como proceso de estruciuración, destructuración y reestructuración" (Gurvitch).

Planteado el todo social como la estructuración dialéctica de los elementos que lo configuran, no será posible comprender el orden jurídico sino a partir de los elementos económicos, sociales, etc., y a su vez estos elementos no adquirirán significación jurídica sino a partir de un orden de Derecho. Pero cada uno de estos aspectos de lo social constituye igualmente respectivas estructuras que se componen también de nuevas subestructuras. De esta manera, la sociedad es una estructura de estructuras -o mejor, para no descuidar la temporalidad, una estructuración de estructuraciones - basada en los diferentes campos de la actividad práctica del hombre como ser-en-el-mundo y ser-con-otros. Pero, en cada momento histórico, ciertas actividades del hombre en su trato con el mundo, ciertas "necesidades" de mundo, pueden aparecer més importantes que otras y por eso el hombre busca satisfacerlas con prioridad. Estas actividades representarán entonces el soporte de las demás, el substratum sobre el que se edifica la praxis social: a este nivel primario de estructuración lo denomina "infraestructura". En la sociedad occidental está conformado por las necesidades económicas, pero se comprueba la existencia de otras sociedades con infraestructuras diferentes, como es el caso de las infraestructuras sociales de ciertas sociedades primitivas en las que las relaciones de parentesco y consanguinidad están en la base de su estructuración (Lévy-Strauss). La "superestructura" será el conjunto de estructuras - entre las que se encuentra el Derecho - que se apoyan en la estructura dominante y la expresan en los diferentes aspectos de la realidad social. Esta transposición de la infraestructura en el Derecho puede producirse por dos caminos. En primer lugar, hay casos de transposición inmediata en las que la infraestructura se hace presente en el Derecho sin pasar por estructuras intermedias: asi sucede en algunas situaciones de facto en las que, aun cuando jurídicamente no tienen valor, la importancia de las actividades sociales subyacentes lleva a asignarles ciertos efectos jurídicos. Empero, en la mayoría de los casos la transposición puede encontrarse obscurecida por un gran número de niveles significativos intermedios al punto que su relación con la infraestructura sólo pueda descubrirse a través de la noción de "visión del mundo". Esta consiste en una actitud global y que resulta de la opción total del hombre frente a su mundo. No se trata de una conceptualización que se ubicaria, por consiguiente, al nivel de la superestructura en tanto que "reflexión"; es más bien una actitud totalizante de base que, aun cuando adquiere coherencia conceptual al nivel de la superestructura, impregna todos los niveles estructurales.

Después de exponernos el proceso de materialización sociológica de las actitudes ontológicas que constituian la totalización del hecho y del valor, Poulantzas cree conveniente recordar una vez más su distincićn entre valores "válidos" y "no-válidos". No debe pensarse que todo valor transpuesto en el orden jurídico a través de la praxis social, es por ese solo hecho, válido. Esto nos haría caer en un positivismo que el autor ha tenido especial cuidado en evitar. No todos los valores son "válidos" sino sólo aquellos que corresponden a una autenticidad de la existencia, es decir, que eligen a cada instante su propia libertad y la de los otros. Estos criterios deben traducirse en términos concretos frente a cada situación social e histórica: un universo jurídico será "válido" cuando realiza la libertad "práctica" de hombres 
reales que viven en común dentro de una situación concreta y se esfuerzan por crear un mundo humano donde cada hombre adquiera prácticamente su dignidad de sujeto: el Derecho será tanto más justo en la medida que suprima la alienación del hombre, su reificación o "cosificación".

Poulantzas conserva la expresión de "Derecho Natural" para esta concepción axiológica, afirmando que dicho término agrupa en la Historia de la Filosofía del Derecho todas las tentativas de descubrir criterios de justicia, medios de evaluar el Derecho positivo más allá del hecho mismo de su positividad. Sin embargo, advierte que no debe confundirse su posición con las que podrían derivarse de un jusnaturalismo ligado a las nociones de trascendencia, esencia o "naturaleza" humana: para él, es la existencia concreta y la praxis humana que constituyen la naturaleza de las cosas y que estructuran genéticamente los criterios axiológicos de evaluación de un orden jurídico positivo. En consecuencia, el Derecho $\mathrm{Na}$ tural no está "hecho" sino que estará "haciéndose" mientras existan hombres: es la reivindicación por el hombre de su propia humanidad, que debe concretarse en el interior de cada situación determinada. Por otra parte, la denominación "Derecho Natural" no debe llevarnos a pensar que existe otro "Derecho" — en el sentido estricto - más allá del Derecho positivo: el Derecho posee una especificidad propia que no se manifiesta sino a través de su positividad. El llamado Derecho Natural es más bien el conjunto de valores que nos permiten juzgar desde fuera ese Derecho positivo.

\section{1}

No puede ocultársenos el interés de una filosofía como la expuesta que pretende dar cuenta de la importancia fundamental de las exigencias históricas y sociales que condicionan la existencia humana, conservando al mismo tiempo muy viva una idea del hombre como libertad esencial, como creador de valor, como responsable a través de su acción del mundo en que vive y no como un simple subproducto de lo económico según lo concibe una cierta concepción del marxismo. Notemos además que la Filosofía del Derecho de Poulantzas, en tanto que explicación del fenómeno jurídico, no se presenta como radicalmente incompatible a una apertura del hombre hacia la Trascendencia, no elimina necesariamente una dimensión del hombre como "ser-abierto-a-Dios". En efecto, la búsqueda de un sentido inmanente a lo real, la sustentación del valor en la actividad libre de los hombres en el interior de sus circunstancias, no excluye por sí misma la hipótesis de un Dios que ha creado al hombre a su imagen y semejanza y que, por consiguiente, lo ha creado como creador a su vez de significaciones, de valores. En esta forma, podemos decir que Dios ha hecho al hombre como libertad y por ello, éste sólo puede realizarse en cuanto hombre, sólo puede cumplir su destino humano, escogiéndose a sí mismo y a los demás en tanto que sujetos, es decir, proyectándose sobre las cosas en compañía de los otros hombres, cargando de significaciones humanas al mundo que le rodea, deviniendo cada vez más libre a través de una mayor participación en la determinación de las formas concretas de su existencia-en-el-mundo-con-los-otros. Dentro de esta perspectiva, la economía, la técnica, la política o el Derecho constituyen parte del Plan de Dios aun siendo muy humanas, porque su realización ha sido encomendada al hombre: la "libertad en situación" del hombre en el mundo se encuentra fundada en una relación anterior hombre-Dios que crea la existencia humana como libertad; la totalidad estructural del hecho y el valor que encontramos en el seno de la existencia humana está inmersa a su vez en una Totalidad anterior que constituye la significación de la existencia misma.

Cabe señalar que, en base a estos planteamientos, puede hablarse - como lo hace Poulantzas - de una "naturaleza de las cosas". Sin embargo, este término pretende designar en tal caso no una esencia sino una existencia, no las características predeterminadas e inmutables de un objeto-hombre sino precisamente esa condición particular del sujeto como creador, como "inventor" de su propia vida. Aceptar la creación del hombre por Dios no altera lo dicho porque no puede entenderse la Creación como un acto de "cosificación" suprema, no es una objetivación inicial que "fija" al hombre dentro de ciertas pautas; por el contrario, es la creación de una libertad, es la creación de un creador, de un "sujeto" cuya única determinación es la de crear sus propias determinaciones. Es en este sentido que ha podido afirmarse paradójicamente del hombre que es el único ser cuya naturaleza consiste en no tener naturaleza. Por este motivo, considerando la connotación "esencialista" del término "naturaleza" creemos que el uso que hace de él Poulantzas dentro de su filosofía da lugar a confusión. $Y$ aún más grave es el caso respecto de "Derecho Natural", locución que ha sido ampliamente utilizada para designar un sistema de derechos irremediablemente individuales, pretendidamente anteriores a la sociedad $y$ al Derecho $-y$, por tanto, independientes de la praxis social e inmutables en el tiempo y en el espacio - de los cuales se "deducirían" por implicaciones 
sucesivas una colección de reglas concretas que participarian de los rasgos antes mencionados: en esta forma, fácilmente podría probarse que la facultad de cortar las ramas del árbol del vecino que invaden nuestra propiedad, constituye también un "derecho natural" inalienable. Es evidente que tal concepción se encuentre en las antípodas de las tesis sostenidas por Poulantzas $y$, por ese motivo, resulta inconveniente imponerles un nombre en común.

Merece especialmente destacarse en el libro del señor Poulantzas la concepción bastante flexible de la "infraestructura". Es conocido que en el marxismo "tradicional", la infraestructura estaba conformada únicamente por el nivel económico - las relaciones de producción - que se constituia así como el factor determinante de la estructuración social. La actividad económica del hombre era el cimiento de su vida integral, al punto de explicar todas las demás actividades humanas. En cambio, para Pulantzas la inf́raestructura no tiene un contenido prefijado: corresponde a aquellas necesidades que los hombres otorgan un valor prioritario en un momento histórico determinado y que no son necesariamente las económicas. En esta forma, se produce una inversión, debida probablemente a las premisas existencialistas: no es lo económico que determina la práxis sino, por el contrario, es la praxis que determina la infraestructura y que eventualmente la hace consistir en necesidades - o meior, actividades para satisfacer necesidades - de carécter económico; todo - incluyendo la infraestructura n uentra así su fuente en la acción práctica de los hombres viviendo en común en un mundo al que deben connuistar. Es preciso anotar también que esta infraestructura así constituida por las preferencias manifestadas por lis hombres a través de una evaluación permanente, se presenta como simplemente dominante y no como un determinismo implacable. Es decir, que la infraestructura no solamente es el resultado de las preferencias o exigencias de hombres concretos actuando en un momento histórico sino que además esta opción de base no puede arrogarse la función de explicar en forma exclusiva la actuación estructurante de los hombres dentro del todo social: aun cuando el papel de la infraestructura sea muy importante, los demás niveles estructurales conservan su especificidad y es necesario tener en cuenta este hecho para evitar una interpretación simplista de los fenómenos sociales basada solamente en su relación con la infraestructura. Es por esta razón que Poulantzas preconiza la adopción de un método interno-externo para el estudio del Derecho: el método interno suministra la visión propiamente juridica; el método externo es más bien una visión genética que pretende descubrir las mediaciones sucesivas a través de las cuales la infraestructura se transpone en superestructura jurídica. Es también este camino que conduce a Poulantzas hasta la noción de "visión del mundo": si afirmamos la especificidad de cada nivel y la riqueza estructural de la realidad social, no cabe duda que la transposición de la infraestructura en superestructura es un proceso complejo, matizado, cuyo análisis exige nuevos instrumentos de trabajo; no puede bastar - como lo ha pretendido una cierta sociología marxista - una simple superposición metodológica de la infraestructura sobre los demás aspectos de la vida social para comprender las relaciones entre ambas.

Lamentablemente, Poulantzas no ha desarrollado sus propias tesis en la línea que había sido esbozada por él mismo. Por el contrario, al pasar a los análisis concretos retoma posiciones más próximas de la ortodoxia marxista, abandonando los nuevos senderos que acababa de desbrozar.

Es así como, después de haber sostenido que la infraestructura no es necesariamente económica, regresa al marxismo clásico afirmando que la sociedad actual descansa sobre una infraestructura económica. Aún cuando el principio ha sido salvado, el análisis de la realidad reintroduce una explicación de tipo simplista que creiamos que habia sido superada. Es posible que una convicción más firme de la flexibilidad de la infraestructura unida a un estudio objetivo de "sociologia de las profundidades", habria revelado un fundamento bastante més complejo para nuestra sociedad actual que las relaciones de producción a secas: la infraestructura habria aparecido quizá como constituida por un conjunto de opciones preferenciales de indole muy diversa, como una combinación peculiar de relaciones del hombre entre las que se encontrarian indudablemente las económicas; pero estas últimas no agotarian su contenido.

Esta preocupación de mantenerse fiel al pensamiento marxista lo lleva también a afirmar que la visión del mundo predominante en una sociedad es la que posee la clase económicamente dominante y que es a través de ella que se comprenden los ordenamientos jurídicos vigentes. Para Poulantzas, es el orden público quien se encarga de preservar de manera particular ciertas formas jurídicas en el tiempo, de garantizar su cumplimiento inevitable: a través del orden público una sociedad se modela a sí misma. Por este motivo, dado que el modelo impuesto corresponde a la visión del mundo dominante, que a su vez es la producida por la clase económicamente dirigente, el orden público constituye la expresión directa de 
esa clase dirigente. Poulantzas insiste en el hecho de que, dentro de nuestra sociedad capitalista occidental, esta clase define su preponderancia a nivel económico, puesto que la infraestructura es en este caso económica. Esto no significa, dice Poulantzas, que dentro de una misma sociedad no coexistan diversas visiones del mundo; por el contrario, paralelamente a la visión preponderante pueden encontrarse elementos de otras visiones del mundo en proceso de formación, pertenecientes a grupos o clases sociales diferentes e incluso antagonistas. Pero como el orden público es la hegemonia de la clase económica dirigente, estas otras visiones aún cuando hubieran tomado participación en la elaboración del Derecho vigente se manifestarán solamente en estructuras juridicas privadas todavia de la garantía que les confiere el orden público.

Sin embargo, estas conclusiones del señor Poulantzas no se compadecen con los datos que nos suministra la sociología ni con el análisis del Derecho positivo. En efecto, sin desconocer el papel primordial que desempeña la clase dirigente en la marcha de una sociedad, la sociologia actual ha demostrado la importante participación de los grupos no dominantes en la formacićn del ordenamiento jurídico, sea en forma indirecta por la necesidad del grupo dominante de plegarse a las exigencias del dominado a fin de conservar un poder que declina, sea en forma directa. A la concepción de las clases como únicos factores activos dentro de una sociedad, se ha agregado ahora la noción de grupos de presión y resulta cada vez más difícil encontrar una correspondencia entre grupos de presión y clases sociales, como pretende Poulantzas. Por otra parte, comprobamos que cuando ciertos aspectos de la visión del mundo de un grupo no dominante logran traducirse en reglas jurídicas, éstas revisten generalmente el carácter de orden público: este es el caso del Derecho Laboral, de la Reforma Agraria, de la planificación, etc., cuyas disposiciones no solamente son de orden público sino que incluso en la mayoría de los casos los derechos subjetivos que crean no son susceptibles de renuncia por los titulares. Aún más, podríamos afirmar que, dentro del ordenamiento jurídico vigente, el orden público está constituido fundamentalmente por las reglas que traducen visiones del mundo diferentes de la visión de la clase económicamente dominante y que las reglas originadas en la visión del mundo de esta última clase son supletorias en su mayoría. (3)

3 Esta comprobación es válida respecto del Perú, pero no negamos que en otros países -como es el caso de Francia- los progresos sociales en el campo del Derecho
Claro está que las tesis de $\mathrm{N}$. Poulantzas podrian defenderse afirmando que este orden público es la expresión de una nueva clase que ha obtenido el poder político y que está representada por el sector medio de la población; es ese caso, ese orden público es también producto de una clase dirigente. Sin embargo, dado que esta nueva clase no detenta el poder económico, tal defensa implicaría negar que la infraestructura está constituida exclusivamente por lo económico y, contrario sensu, admitir que la infraestructura de la sociedad actual está configuarda también por factores sociales y políticos. La contradicción surge así desde todos los extremos del planteamiento.

Finalmente, Nicos Ar. Poulantzas sostiene que algunos filósofos del Derecho estiman como indispensable la nocićn de autonomía privada, pero que, sin negar su utilidad en algunos casos particulares, esta noción no resulta necesaria dentro de la tesis expuesta por él. Describe la autonomía privada como uno de los términos de un dualismo respecto de la persona entre un estatuto individual anterior a la sociedad - los derechos subjetivos "naturales", especialmente la propiedad privada y la libertad de contratación - y un estatuto social. Poulantzas afirma que el hombre no existe "primero" individualmente y "después" con los otros. Hemos dicho que el hombre es un "ser-con" (Mitsein) y, por consiguiente, lo individual y lo social no pueden oponerse a nivel ontológico: "la liberiad-acción individual es la libertad-acción de los hombres que en-compañía-de-los-otros conquistan el mundo para satisfacer sus necesidades". Luego, los hombres no existen como individuos sino como seres sociales que, en ciertas circunstancias, pueden conquistar su individualidad. De lo que se deduce que la autonomia privada no es una consecuencia axiológica necesaria de los elementos ontológicos citados sino más bien un desarrollo eventual.

Creemos que el autor confunde aquí la noción de autonomía privada con una de sus formas históricas: la descripción que nos hace corresponde a la concepción de Locke que dio origen al individualismo liberal. No cabe duda alguna que esta concepción es incompatible con la filosofía expuesta en el libro que comentamos, y reconocemos en este aspecto lo ceriero de la crítica: las relaciones entre lo social y lo individual no pueden plantearse en términos de oposición y prelación; asimismo,

se manifiesten más bien por vía jurisprudencial y no legal. En esta hipótesis la afirmación de Poulantzas es exacta, pero las conclusiones generales que obtiene de ella no son correctas. 
estas relaciones son variables históricamente, de modo que una sociedad dada puede recortar o ampliar la esfera de lo individual en la medida que ello contribuya a traducir de manera más plena en una realidad determinada el reconocimiento de la libertad concreta del hombre. Sin embargo, Poulantzas se inclina por una primacia de lo social - entendido como "lo colectivo" - que suprime la noción de autonomía privada o al menos le concede un carácter excepcional, lo que encontramos contradictorio con su pensamiento.

En efecto, lo colectivo y lo individual no se oponen en tanto que son dos "momentos" de una totalidad: la existencia social. El hombre es un ser-con-los-otros, lo que supone un "nosotros"; pero este "nosotros" implica a su vez el "yo" y el "tú" que lo constituyen en tanto que sujetos vinculados entre sí. Ahora bien, el solo hecho de hablar de "sujetos" nos remite a la noción de autonomia debido a que éstos son centros de decisión. Sin embargo, esta autonomía no quiere decir aislamiento sino, por el contrario, participación como "sujetos", intervención en la creación de valores en común. Claro está que esto conlleva un núcleo irreductible de individualidad en el seno de lo social: la libertad de cada hombre, su calidad de "sujeto", no puede suprimirse nunca, ya que es justamente ella que entreteje la trama de lo social. Una sociedad que decidiera en común - es decir, con la participación de todos sus miembros - que una parte de ellos fuese esclavizado en provecho de la otra parte, que un grupo de hombres perdiera en cualquier forma su calidad de sujetos, que fuera "cosificado", "objetivizado", una tal sociedad entraría en contradicción con los principios expuestos por el señor Poulantzas porque estaría creando un valor "no-válido", un fin que no condice con la existencia auténtica del ser humano. Por consiguiente, la autonomía privada - que implica el reconocimiento del "otro" en tanto que sujeto - debe ser siempre salvaguardada.

Ahora bien, hasta aqui las observaciones que hemos formulado a la negación de la autonomía privada por $\mathrm{N}$. Poulantzas se refieren al plano que él denomina "ontológico". Pero los términos "colectivo" e "individual" deben transponerse en la coyuntura sociológica de manera de encontrar, dentro del cuadro que nos presenta cada situación dada, el sentido concreto del término "autonomía": en ciertas ocasiones, ésta puede exigir la defensa apasionada de la esfera individual frente a la opresión absorbente, "cosificante", de la dictadura; en otras, la auténtica participación del hombre - de todos los hombres - en la sociedad como centros de decisión, como "sujetos", sólo podrá realizarse con un cierto predominio de lo colectivo que puede alcanzar hasta la sustitución de formas históricas de la autonomía como la propiedad privada por otras formas nuevas de organización. $Y$ es así como, adoptando un punto de partida inusitado, habríamos llegado a una "visión del hombre" que un sector del pensamiento católico ha desarrollado particularmente: la noción de "persona" (Mounier). 